\title{
Knowledge and attitudes towards ambulatory treatment of tuberculosis in Kazakhstan
}

Meruyert Darisheva ${ }^{1 *}$, Melissa Tracy², Assel Terlikbayeva ${ }^{1}$, Baurzhan Zhussupov ${ }^{3}$, Neil Schluger $^{4}$ and Tara McCrimmon ${ }^{5}$

\begin{abstract}
Background: Ambulatory based treatment of tuberculosis has been recently introduced in Kazakhstan. We sought to assess the attitudes of the general population, TB patients and their household members towards ambulatory TB treatment and identify how knowledge of TB is associated with these attitudes.

Methods: New pulmonary TB cases and their household and community controls were recruited from three regions of Kazakhstan in 2012-2014. 1083 participants completed audio computer-assisted self interviews to assess their knowledge of TB and attitudes towards ambulatory care. Mixed effects logistic regression models were used to identify factors associated with attitudes toward ambulatory TB treatment.

Results: The proportion of people who considered ambulatory TB treatment as appropriate was very low (24.9\%). Positive attitudes towards ambulatory TB treatment were significantly associated with region of residence, higher level of education, family support and experience with TB. The association between sufficient tuberculosis knowledge and favorable attitude toward ambulatory treatment was stronger among community controls compared to TB patients and their family members.

Conclusions: This study provides insight into attitudes toward ambulatory TB treatment among different groups and the specific influence of TB knowledge on these attitudes. Our findings can inform the process of integration of new TB treatment strategies and the development of appropriate education and advocacy programs in the general population.
\end{abstract}

Keywords: Tuberculosis, TB treatment, Kazakhstan, TB attitude, TB knowledge

\section{Background}

Kazakhstan is an upper middle-income country with a population of 18.7 million [1]. Currently, Kazakhstan has one of the highest Multidrug-Resistant Tuberculosis (MDR TB) burdens in the world [2], with an MDR TB incidence rate of 26 per 100,000, and a drug sensitive TB incidence rate as high as 68 per 100,000 in 2018 [3].

\footnotetext{
* Correspondence: mdarisheva@gmail.com

'Columbia University Global Health Research Center of Central Asia, Almaty, Kazakhstan

Full list of author information is available at the end of the article
}

The TB epidemic is complicated by the emergence of multidrug-resistant strains of $\mathrm{TB}$ that continue to increase and are associated with the worst treatment outcomes [2].

Post-Soviet Kazakhstan inherited the highly vertical Soviet model of tuberculosis control, based on active case finding, individualized $\mathrm{TB}$ treatment, and high levels of hospitalization [4]. TB treatment practices, including hospitalizations for long periods with significant levels of interruption, treatment default, and failure to standardize treatment regimens have likely contributed

(c) The Author(s). 2020 Open Access This article is licensed under a Creative Commons Attribution 4.0 International License, which permits use, sharing, adaptation, distribution and reproduction in any medium or format, as long as you give appropriate credit to the original author(s) and the source, provide a link to the Creative Commons licence, and indicate if changes were made. The images or other third party material in this article are included in the article's Creative Commons licence, unless indicated otherwise in a credit line to the material. If material is not included in the article's Creative Commons licence and your intended use is not permitted by statutory regulation or exceeds the permitted use, you will need to obtain permission directly from the copyright holder. To view a copy of this licence, visit http://creativecommons.org/licenses/by/4.0/ The Creative Commons Public Domain Dedication waiver (http://creativecommons.org/publicdomain/zero/1.0/) applies to the data made available in this article, unless otherwise stated in a credit line to the data. 
to a high level of drug resistance to anti-tuberculosis medications [5].

To control a growing epidemic of TB, Kazakhstan introduced the National Tuberculosis Program (NTP) and World Health Organization's Directly Observed Treatment, Short-Course (WHO's DOTS) strategy in 1998. Through these efforts, TB incidence rates declined in the country; nevertheless TB still remains a major public health concern in Kazakhstan due to the rapid increase of drug-resistant strains. Inpatient models of TB treatment are expensive for health systems [6]. Ambulatory treatment, administered in outpatient settings, has been found effective in multiple countries [7, 8]. Since 2011, WHO has been recommending ambulatory treatment of both drug-susceptible and MDR-TB in outpatient settings [9]. Treatment at the ambulatory level is more cost-effective, reduces the risk of nosocomial transmission of drug resistant strains, and facilitates patients receiving comprehensive health services, including psychosocial care and support [10-12]. Furthermore, ambulatory treatment helps to shift treatment closer to places where patients live and allows patients to be more independent [13].

As Kazakhstan historically relied on a hospitalbased model of TB treatment, the implementation of ambulatory TB care faced many structural challenges. WHO experts think that Kazakhstan still conducts excessive hospitalization for TB, with a system that discourages ambulatory care [11], and that reforms of Kazakhstan's primary health care system are necessary to avoid unnecessary hospitalizations for TB [14]. Following WHO recommendations, Kazakhstan has been moving toward an ambulatory model of TB treatment and cutting the numbers of hospital beds. TB services have been intergrated into primary care and include daily provision of medications, hospital-replacement technologies (day care, home hospital, video-controlled therapy, mobile team for those who can not adhere to DOTS, adverse effects and comorbid conditions treatment, and psychosocial counseling for TB patients). TB diagnosis can be made by TB specialist at primary care and need to be confirmed with the Centralized Medical Advisory Commission [15, 16].

For this model to succeed, patients and the general public must be accepting of this approach. However, little is known about patient, family, and general population preferences for ambulatory $\mathrm{TB}$ care models. It was proved that better knowledge can lead to positive attitude and subsequently to good practices [17]. Insufficient knowledge about the disease might contribute to stigmatization and negative attitudes toward $\mathrm{TB}$ patients being treated in primary care among general population [18].
The objective of this study was to assess attitudes toward ambulatory TB treatment among TB patients, their household contacts and community dwellers. In particular, we aimed to examine the association between TB knowledge and attitudes toward ambulatory treatment. Our findings will provide information facilitating the adoption of the new TB treatment strategies and the development of appropriate education and advocacy programs in Kazakhstan.

\section{Methods}

This study utilizes data from a case-control study among new pulmonary TB cases (index case), and both a matched household control and community control; additional results have previously been published [1921]. We selected three regions in Kazakhstan (Almaty City, Almaty Oblast and Kostanay Oblast) that represented a range of TB burden as determined by the epidemiological surveillance from the National TB Center [21]. Within these regions we employed a cluster sampling approach, using SAS 9.2 to randomly select subregions, and calculated estimated recruitment numbers based on incidence data in these sub-regions. Within each region, index cases were identified by TB doctors as pulmonary $\mathrm{TB}$ cases recently diagnosed (within 90 days). The doctor was trained to introduce the study to all new cases of TB and to refer them to be prescreened by research staff. During the prescreening interview, research staff introduced the study to potential participants, administered consent and conducted a short 10min prescreening survey to identify whether the case met eligibility criteria. Eligibility criteria included: (1) age 18 years and older; (2) permanent residence address for 3 months or more; (3) speaking Russian or Kazakh language fluently; and (4) absence of severe psychiatric condition that might impede their ability to provide informed consent. To be included in the study, all index cases were required to have an adult household member available to serve as a control. Both household and community controls were matched on the following criteria: age difference within 10 years and same household or geographic area to ensure similar environmental factors and socio-economic status. Controls were also required to meet the same primary eligibility criteria as the index cases described above.

The community control was sampled either from the same building as the index case using a Kish table (urban settings) or within a limited geographic area (rural settings) by choosing random direction (pen method) from the index case residence, and was thus matched to the index case on geographic location. More information on selection is provided in the Supplement. In total, 1083 participants were recruited into the study, 
including 387 cases, 342 household controls, 354 community controls.

The study received approvals from the Columbia University Institutional Review Board, Kazakhstan's National Scientific Center of Physiopulmonology (KNSCP) and the Center of Life Sciences of Nazarbayev University (CLS of NU).

\section{Data collection}

Data was collected through 60-min audio computerassisted self-interview (ACASI). The study instrument was programmed and presented in Kazakh or Russian in Illume Survey Manager. Interviews were conducted in private rooms, with a research assistant available to assist participants if needed. Data were collected from September 2012 to March 2014.

Sociodemographic information was collected on all participants, including age, gender, employment status, educational level, marital status, ethnicity, living in an urban or rural setting, and current debt. These data were used as covariates in the analysis.

Attitudes toward ambulatory TB treatment were assessed with the question: "When a person first discovers that he or she has tuberculosis, how should that person be treated: hospitalized, treated at home, or hospitalized and then continue treatment at home?" Participants answering "TB patients should be only treated in hospitals" were classified as having negative attitudes to ambulatory treatment. Participants answering "TB patients should be treated in hospital and then continue treatment at home" or "TB patients should be treated at home" were considered to have a positive attitude to TB treatment provided in outpatient settings.

The aggregated variable "TB knowledge" was created through combination of responses for three TB-related questions (TB signs and symptoms, route of transmission and way of treatment). Sufficient level of TB knowledge was defined as (1) correctly selecting at least three TB symptoms from a multiple-choice list; (2) correctly selecting the airborne route of transmission from a multiple-choice list; and (3) correctly selecting the statement that tuberculosis can be completely cured with specific drugs and treatment regimens [22].

Perceived social support was measured as an ordinal variable ranging from 1 (very strongly disagree) to 7 (very strongly agree) by using the 'Multidimensional Scale of Perceived Social Support' (MSPSS), which has been previously used in Kazakhstan [23]. This measure includes three subscales pertaining to perceived support from family, friends, and one's significant other, respectively, with 4 items for each subscale; a score of 6 or higher on a given subscale was considered a high level of support. The MSPSS has been shown to have good internal and test-retest reliability and good validity [24].

\section{Data analysis}

Statistical analysis was performed using $\mathrm{R}$ version 3.3.2. Univariate statistics were examined to describe the study population, determine whether values for all measures of interest were plausible and consistent, and to assess the amount of missing data. For categorical variables, we examined frequencies, whereas for continuous variables (i.e., age), we calculated the mean and standard deviation and checked for outliers. We performed Chi-square tests to examine the associations between the outcome and independent variables.

We used the function 'glmer' in package 'Ime4' to fit a generalized (binomial) linear mixed-effects model with random intercept for each triplet. This modeling procedure allows us to appropriately account for the matching of controls to cases, and serves as an alternative to conditional logistic regression in this situation where case status is not our outcome of interest. We included all variables with epidemiological and statistical significance in the full model and used backward selection to find the optimal model. Variables that were significantly associated with the outcome at $p<0.05$, as well as our primary exposure of interest (level of TB knowledge), were retained in the final model. To examine potential effect measure modification of the association between $\mathrm{TB}$ knowledge and attitudes toward ambulatory treatment by participant group (i.e., cases, family controls, and community controls), we added interaction terms to the final model.

\section{Results}

Sociodemographic characteristics of study participants are shown in Table 1.

The proportion of study participants with sufficient TB knowledge was highest among cases (67.7\%), followed by household controls (52.3\%) and community controls $(47.7 \%)$. Ninety two percent of respondents correctly knew that TB can be completely treated with specific drugs and regimen. Ninety seven percent of respondents was willing to take a family member at home for further treatment after he/she completed the hospital treatment.

Among TB cases, 20\% of respondents reported having someone from their family diagnosed with TB (vs. $13.8 \%$. among community control) and $18.9 \%$ of $\mathrm{TB}$ cases reported having someone with TB among their frequent contacts (friends, neighbors, relatives) (vs. 21.2\% among community control).

The majority of respondents answered that TB patients should be only treated in hospitals. The proportions of respondents with positive attitudes toward outof-hospital TB treatment (either alone or in combination with hospitalization) were significantly higher among TB patients (27.6\%) and their household controls (27.8\%). 
Table 1 Socio-demographic and other characteristics of the study population $(N=1083)$

\begin{tabular}{|c|c|c|c|c|c|c|c|c|}
\hline \multirow{3}{*}{ Characteristic } & \multicolumn{2}{|c|}{ Total } & \multirow{2}{*}{\multicolumn{2}{|c|}{$\frac{\text { TB cases }}{(N=387)}$}} & \multirow{2}{*}{\multicolumn{2}{|c|}{$\frac{\text { Household controls }}{(N=342)}$}} & \multirow{2}{*}{\multicolumn{2}{|c|}{$\begin{array}{l}\text { Community controls } \\
(N=354)\end{array}$}} \\
\hline & \multicolumn{2}{|c|}{$(N=1083)$} & & & & & & \\
\hline & $n$ & $\%$ & $\mathrm{n}$ & $\%$ & $\mathrm{n}$ & $\%$ & $n$ & $\%$ \\
\hline \multicolumn{9}{|l|}{ Gender } \\
\hline Male & 507 & 46.8 & 207 & 53.5 & 126 & 36.8 & 174 & 49.2 \\
\hline Female & 576 & 53.2 & 180 & 46.5 & 216 & 63.2 & 180 & 50.8 \\
\hline Age, in years (Mean $[S D]$ ) & \multicolumn{2}{|c|}{39.0 [13.1] } & \multicolumn{2}{|c|}{$35.5[12.8]$} & \multicolumn{2}{|c|}{$40.9[12.8]$} & \multicolumn{2}{|c|}{$41.1[12.8]$} \\
\hline $18-29$ & 316 & 29.2 & 158 & 40.8 & 78 & 22.8 & 80 & 22.6 \\
\hline $30-39$ & 270 & 24.9 & 95 & 24.5 & 85 & 24.9 & 90 & 25.4 \\
\hline $40-49$ & 236 & 21.8 & 66 & 17.1 & 84 & 24.6 & 86 & 24.3 \\
\hline $50-59$ & 197 & 18.2 & 54 & 14.0 & 73 & 21.3 & 70 & 19.8 \\
\hline$\geq 60$ & 64 & 5.9 & 14 & 3.6 & 22 & 64.0 & 28 & 7.9 \\
\hline \multicolumn{9}{|l|}{ Ethnicity } \\
\hline Kazakh & 699 & 64.5 & 259 & 66.9 & 228 & 66.7 & 212 & 59.9 \\
\hline Russian & 226 & 20.9 & 77 & 19.9 & 66 & 19.3 & 83 & 23.4 \\
\hline Others & 158 & 14.6 & 51 & 13.2 & 48 & 14.0 & 59 & 16.7 \\
\hline \multicolumn{9}{|l|}{ Marital status } \\
\hline Married & 747 & 69.0 & 241 & 62.3 & 266 & 77.8 & 240 & 67.8 \\
\hline Single & 336 & 31.0 & 146 & 37.7 & 76 & 22.2 & 114 & 32.2 \\
\hline \multicolumn{9}{|l|}{ Level of education ${ }^{a}$} \\
\hline Primary and secondary school & 99 & 9.1 & 34 & 8.8 & 35 & 10.2 & 30 & 8.5 \\
\hline High school & 400 & 36.9 & 153 & 39.5 & 118 & 34.5 & 129 & 36.4 \\
\hline Vocational education & 361 & 33.3 & 128 & 33.1 & 121 & 35.4 & 112 & 31.6 \\
\hline Higher education & 223 & 20.6 & 72 & 18.6 & 68 & 19.9 & 83 & 23.4 \\
\hline \multicolumn{9}{|l|}{ Current employment status } \\
\hline Employed & 660 & 60.9 & 229 & 59.2 & 209 & 61.1 & 222 & 62.7 \\
\hline Unemployed & 423 & 39.1 & 158 & 40.8 & 133 & 38.9 & 132 & 37.3 \\
\hline \multicolumn{9}{|l|}{ Currently in debt ${ }^{\mathrm{b}}$} \\
\hline No & 683 & 63.1 & 251 & 64.9 & 198 & 57.9 & 234 & 66.1 \\
\hline Yes & 400 & 36.9 & 136 & 35.1 & 144 & 42.1 & 120 & 33.9 \\
\hline \multicolumn{9}{|l|}{ Region } \\
\hline Almaty city & 133 & 12.3 & 56 & 14.5 & 33 & 9.6 & 44 & 12.4 \\
\hline Almaty oblast & 524 & 48.4 & 185 & 47.8 & 170 & 49.7 & 169 & 47.7 \\
\hline Kostanay oblast & 426 & 39.3 & 146 & 37.7 & 139 & 40.6 & 141 & 39.8 \\
\hline \multicolumn{9}{|l|}{ High level of family support ${ }^{c}$} \\
\hline No & 203 & 18.7 & 66 & 17.1 & 67 & 19.6 & 70 & 19.8 \\
\hline Yes & 880 & 81.3 & 321 & 82.9 & 275 & 80.4 & 284 & 80.2 \\
\hline \multicolumn{9}{|l|}{ High level of friend support ${ }^{d}$} \\
\hline No & 342 & 31.6 & 129 & 33.3 & 114 & 33.3 & 99 & 28.0 \\
\hline Yes & 741 & 68.4 & 258 & 66.7 & 228 & 66.7 & 255 & 72.0 \\
\hline \multicolumn{9}{|c|}{ High level of support from significant other ${ }^{e}$} \\
\hline No & 179 & 16.5 & 55 & 14.2 & 63 & 18.4 & 61 & 17.2 \\
\hline Yes & 904 & 83.5 & 332 & 85.8 & 279 & 81.6 & 293 & 82.8 \\
\hline \multicolumn{9}{|l|}{ Tuberculosis knowledge } \\
\hline Insufficient & 473 & 43.7 & 125 & 32.3 & 163 & 47.7 & 185 & 52.3 \\
\hline
\end{tabular}


Table 1 Socio-demographic and other characteristics of the study population ( $N=1083)$ (Continued)

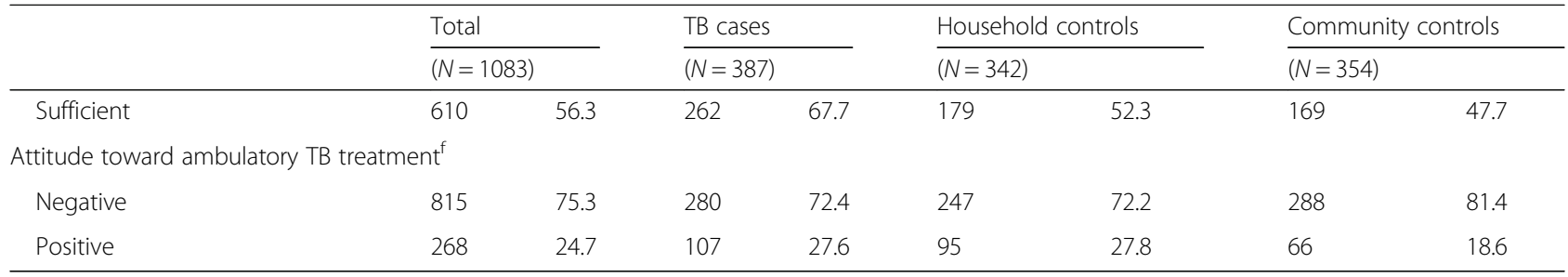

a "Primary and secondary school" reflect schooling up to grade 9, whereas "high school" reflects grades 10-11

b Assessed with the question: "Are you currently in debt?"

c High level of support is indicated by a score of 6 or more on the Family Subscale of the Multidimensional Scale of Perceived Social Support

${ }^{d}$ High level of support is indicated by a score of 6 or more on the Friends Subscale of the Multidimensional Scale of Perceived Social Support

e High level of support is indicated by a score of 6 or more on the Significant Other Subscale of the Multidimensional Scale of Perceived Social Support

f Positive attitude toward ambulatory TB treatment is indicated by responses of "TB patients should be treated in hospital and then continue treatment at home"

or "TB patients should be treated at home" to a question about how a newly diagnosed person with TB should be treated

Only $18.6 \%$ of community controls agreed that TB patients can be initially hospitalized and then continue treatment at home or receive treatment at home from the first day.

Bivariate analyses showed an association between positive attitude toward ambulatory $\mathrm{TB}$ treatment and $\mathrm{TB}$ knowledge and other covariates (Table 2). A positive attitude toward ambulatory TB treatment was significantly associated with the region (with higher proportions of respondents in Almaty oblast indicating positive attitudes at $34.0 \%$ vs. 14.8 and $20.3 \%$ in Kostanay oblast and Almaty city, respectively; $p<0.001$ ); perceived family support (with $36.0 \%$ of participants with low family support reporting positive attitudes towards ambulatory TB treatment, compared to $22.2 \%$ among those with high family support; $p<0.001$ ); and level of TB knowledge (with $28.2 \%$ of those with sufficient TB knowledge reporting positive attitudes, compared to $20.3 \%$ of those with insufficient TB knowledge; $p<0.001$ ). Relations between perceived support from significant others and positive attitudes towards ambulatory TB treatment were similar to those observed for perceived family support, whereby those with higher levels of support considered the in-hospital TB care model as more appropriate. Friends' support was not significantly associated with attitude toward TB treatment, nor were demographic or socioeconomic characteristics, including gender, age, marital status, level of education, ethnicity and current employment status.

Bivariate analyses stratified by the case-control status of respondents demonstrated that sufficient TB knowledge and positive TB attitudes were significantly associated among community controls $(\mathrm{OR}=2.22,95 \% \mathrm{CI}=$ $1.28-3.86)$, but not among $\mathrm{TB}$ cases $(\mathrm{OR}=1.17 ; 95 \%$ $\mathrm{CI}=0.72-1.89)$ or household controls $(\mathrm{OR}=1.36$; $95 \%$ $\mathrm{CI}=0.85-2.20)$.

The final mixed effect logistic regression model (Table 3) includes the following independent variables: case-control status, TB knowledge, level of education, region and perceived family support.
The multivariable analysis showed that living in Almaty oblast was associated with higher odds of positive attitude toward ambulatory $\mathrm{TB}$ treatment $(\mathrm{OR}=4.55$; 95\% CI $=2.68-7.72$ compared to living in Kostanay oblast), whereas reporting high family support was associated with lower odds of positive $\mathrm{TB}$ attitude $(\mathrm{OR}=0.35$; $95 \% \mathrm{CI}=0.22-0.55$ ), adjusting for case-control status, TB knowledge, and level of education. Current TB experience in the form of being a TB patient or sharing a household with a TB patient was associated with a positive attitude toward ambulatory model of $\mathrm{TB}$ treatment $(\mathrm{OR}=2.07 ; 95 \% \mathrm{CI}=1.35-3.17$ for $\mathrm{TB}$ cases and $\mathrm{OR}=$ 1.92; $95 \% \mathrm{CI}=1.25-2.95$ for household controls, both compared to community controls). In this adjusted model, sufficient level of TB knowledge was not significantly associated with positive TB treatment attitude $(\mathrm{OR}=1.15 ; 95 \% \mathrm{CI}=0.76-1.73)$. High school education was associated with lower odds of positive TB attitude as compared to higher education $(\mathrm{OR}=0.51 ; 95 \% \mathrm{CI}=$ $0.30-0.87)$.

Given the evidence for effect modification of the association between TB knowledge and TB treatment attitudes by participant group in bivariate analyses, we added interaction terms for TB knowledge and respondent group in the full multivariable model (Table 4).

Though the interaction between TB knowledge and case-control status was not statistically significant in this adjusted model $(p=0.235)$, the estimated interaction effects suggest that the association between attitude toward ambulatory TB treatment and TB knowledge varies dependent on disease status and on experience of living with someone who has had active TB. In particular, in the interactions model, level of ТВ knowledge has a marginally significant association with positive attitude towards ambulatory TB treatment among community controls $(\mathrm{OR}=1.79 ; 95 \% \mathrm{CI}=0.89-3.61)$. Among those with sufficient $\mathrm{TB}$ knowledge, the association between current TB experience and the outcome variable is stronger for both $\mathrm{TB}$ cases $(\mathrm{OR}=2.96 ; 95 \% \mathrm{CI}=1.44$ 6.08) and household controls ( $\mathrm{OR}=2.79 ; 95 \% \mathrm{CI}=1.42-$ 
Table 2 Bivariate associations between positive attitude toward ambulatory TB treatment and participant characteristics ( $N=1083$ )

\begin{tabular}{|c|c|c|c|c|c|c|c|c|c|c|c|c|}
\hline \multirow[b]{4}{*}{ Characteristic } & \multicolumn{12}{|c|}{ Positive attitude toward ambulatory TB treatment (full or combined with hospitalization) ${ }^{a}$} \\
\hline & \multicolumn{3}{|l|}{ Total } & \multicolumn{3}{|c|}{ TB cases } & \multicolumn{3}{|c|}{ Household controls } & \multicolumn{3}{|c|}{ Community controls } \\
\hline & \multicolumn{3}{|c|}{$(N=1083)$} & \multicolumn{3}{|c|}{$(N=387)$} & \multicolumn{3}{|c|}{$(N=342)$} & \multicolumn{3}{|c|}{$(N=354)$} \\
\hline & $\mathrm{n}$ & $\%$ & p-value & $\mathrm{n}$ & $\%$ & p-value & $\mathrm{n}$ & $\%$ & $p$-value & $\mathrm{n}$ & $\%$ & $p$-value \\
\hline \multicolumn{13}{|l|}{ Gender } \\
\hline Male & 134 & 23.3 & 0.228 & 59 & 28.5 & 0.687 & 39 & 31.0 & 0.317 & 36 & 20.7 & 0.331 \\
\hline Female & 134 & 26.4 & & 48 & 26.7 & & 56 & 25.9 & & 30 & 16.7 & \\
\hline \multicolumn{13}{|l|}{ Age, in years (Mean [SD]) } \\
\hline $18-29$ & 77 & 24.4 & 0.911 & 45 & 28.5 & 0.897 & 18 & 23.1 & 0.719 & 14 & 17.5 & 0.969 \\
\hline $30-39$ & 69 & 25.6 & & 25 & 26.3 & & 25 & 29.4 & & 19 & 21.1 & \\
\hline $40-49$ & 54 & 22.9 & & 16 & 24.2 & & 22 & 26.2 & & 16 & 18.6 & \\
\hline $50-59$ & 50 & 25.4 & & 16 & 29.6 & & 22 & 30.1 & & 12 & 17.1 & \\
\hline$\geq 60$ & 18 & 28.1 & & 5 & 35.7 & & 8 & 36.4 & & 5 & 17.9 & \\
\hline \multicolumn{13}{|l|}{ Ethnicity } \\
\hline Kazakh & 178 & 25.5 & 0.761 & 69 & 26.6 & 0.818 & 68 & 29.8 & 0.472 & 41 & 19.3 & 0.906 \\
\hline Russian & 53 & 23.5 & & 23 & 29.9 & & 15 & 22.7 & & 15 & 18.1 & \\
\hline Others & 37 & 23.4 & & 15 & 29.4 & & 12 & 25.0 & & 10 & 16.9 & \\
\hline \multicolumn{13}{|l|}{ Marital status } \\
\hline Married & 180 & 24.1 & 0.460 & 65 & 27.0 & 0.702 & 76 & 28.6 & 0.540 & 39 & 16.3 & 0.093 \\
\hline Single & 88 & 26.2 & & 42 & 28.8 & & 19 & 25.0 & & 27 & 23.7 & \\
\hline \multicolumn{13}{|l|}{ Level of education ${ }^{b}$} \\
\hline Primary and secondary school & 22 & 22.2 & 0.121 & 7 & 20.6 & 0.131 & 8 & 22.9 & 0.726 & 7 & 23.3 & 0.509 \\
\hline High school & 86 & 21.5 & & 37 & 24.2 & & 30 & 25.4 & & 19 & 14.7 & \\
\hline Vocational education & 104 & 28.8 & & 45 & 35.2 & & 37 & 30.6 & & 22 & 19.6 & \\
\hline Higher education & 56 & 25.1 & & 18 & 25.0 & & 20 & 29.4 & & 18 & 21.7 & \\
\hline \multicolumn{13}{|l|}{ Current employment status } \\
\hline Employed & 159 & 24.1 & 0.533 & 60 & 26.2 & 0.443 & 60 & 28.7 & 0.630 & 39 & 17.6 & 0.500 \\
\hline Unemployed & 109 & 25.8 & & 47 & 29.7 & & 35 & 26.3 & & 27 & 20.5 & \\
\hline \multicolumn{13}{|l|}{ Currently in debt ${ }^{c}$} \\
\hline No & 179 & 26.2 & 0.145 & 39 & 28.7 & 0.739 & 30 & 20.8 & 0.014 & 20 & 16.7 & 0.494 \\
\hline Yes & 89 & 22.3 & & 68 & 27.1 & & 65 & 32.8 & & 46 & 19.7 & \\
\hline \multicolumn{13}{|l|}{ Region } \\
\hline Almaty city & 27 & 20.3 & $<0.001$ & 11 & 19.6 & $<0.001$ & 7 & 21.2 & 0.001 & 9 & 20.5 & 0.002 \\
\hline Almaty oblast & 178 & 34.0 & & 72 & 38.9 & & 63 & 37.1 & & 43 & 25.4 & \\
\hline Kostanay oblast & 63 & 14.8 & & 24 & 16.4 & & 25 & 18.0 & & 14 & 9.9 & \\
\hline \multicolumn{13}{|l|}{ High level of family support ${ }^{d}$} \\
\hline No & 73 & 36.0 & $<0.001$ & 26 & 39.4 & 0.019 & 27 & 40.3 & 0.011 & 20 & 28.6 & 0.017 \\
\hline Yes & 195 & 22.2 & & 81 & 25.2 & & 68 & 24.7 & & 46 & 16.2 & \\
\hline \multicolumn{13}{|l|}{ High level of friend support ${ }^{e}$} \\
\hline No & 92 & 26.9 & 0.264 & 33 & 25.6 & 0.520 & 37 & 32.5 & 0.172 & 22 & 22.2 & 0.281 \\
\hline Yes & 176 & 23.8 & & 74 & 28.7 & & 58 & 25.4 & & 44 & 17.3 & \\
\hline \multicolumn{13}{|c|}{ High level of support from significant other ${ }^{f}$} \\
\hline No & 62 & 34.6 & 0.001 & 21 & 38.2 & 0.059 & 23 & 36.5 & 0.087 & 18 & 29.5 & 0.017 \\
\hline Yes & 206 & 22.8 & & 86 & 25.9 & & 72 & 25.8 & & 48 & 16.4 & \\
\hline
\end{tabular}

Tuberculosis knowledge 
Table 2 Bivariate associations between positive attitude toward ambulatory TB treatment and participant characteristics $(N=1083)$ (Continued)

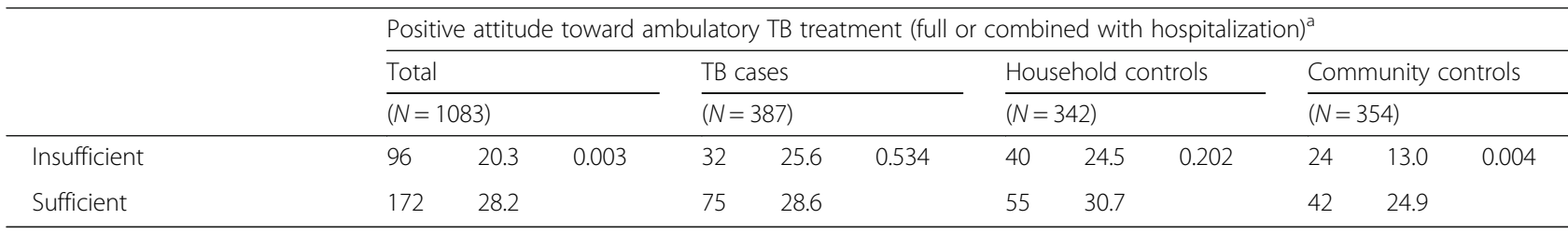

"Positive attitude toward ambulatory TB treatment is indicated by responses of "TB patients should be treated in hospital and then continue treatment at home" or "TB patients should be treated at home" to a question about how a newly diagnosed person with TB should be treated

b "Primary and secondary school" reflect schooling up to grade 9, whereas "high school" reflects grades 10-11

"Assessed with the question: "Are you currently in debt?"

${ }^{d}$ High level of support is indicated by a score of 6 or more on the Family Subscale of the Multidimensional Scale of Perceived Social Support

e High level of support is indicated by a score of 6 or more on the Friends Subscale of the Multidimensional Scale of Perceived Social Support

${ }^{f}$ High level of support is indicated by a score of 6 or more on the Significant Other Subscale of the Multidimensional Scale of Perceived Social Support

5.48) as compared to community controls. These interaction effects are illustrated in Fig. 1.

\section{Discussion}

The majority of respondents in all case-control groups strongly support the idea that TB should be only treated in hospitals. Although most of respondents in our study had "sufficient" TB knowledge, a significant proportion of respondents were not informed enough about TB (43.7\%). Even though the proportion of community controls with sufficient TB knowledge was lower than the corresponding proportions among TB cases and household controls, TB knowledge among community controls was marginally associated with considering the ambulatory model of TB treatment as appropriate. Insufficient knowledge about the disease might contribute to stigmatization and fear toward patients [25]. The majority of respondents in the Report of a Joint IUAT/WHO Study Group said "they would not live with a TB patient" (93.8\%), "would not share food, clothes or a bath with them" (95.4\%), and "would not hug, kiss or touch them" (97\%) [26]. Since TB is a communicable and highburden disease, it is very important to develop positive attitudes toward TB patients and ambulatory TB treatment among the population of Kazakhstan. Findings that higher levels of knowledge about $\mathrm{TB}$ signs and

Table 3 Results of mixed effects logistic regression models predicting positive attitude toward ambulatory TB treatment

\begin{tabular}{|c|c|c|c|c|}
\hline \multirow[b]{2}{*}{ Characteristic } & \multicolumn{4}{|c|}{ Positive attitude toward ambulatory TB treatment } \\
\hline & beta & OR & $95 \% \mathrm{Cl}$ for OR & $p$-value \\
\hline \multicolumn{5}{|l|}{ Participant group } \\
\hline Community controls & 0.00 & 1.00 & (ref) & - \\
\hline Household controls & 0.65 & 1.92 & $(1.25-2.95)$ & 0.003 \\
\hline New pulmonary TB cases & 0.73 & 2.07 & $(1.35-3.17)$ & 0.001 \\
\hline \multicolumn{5}{|l|}{ Tuberculosis knowledge } \\
\hline Insufficient & 0.00 & 1.00 & (ref) & - \\
\hline Sufficient & 0.14 & 1.15 & $(0.76-1.73)$ & 0.501 \\
\hline \multicolumn{5}{|l|}{ Level of education } \\
\hline Primary and secondary school & -0.55 & 0.58 & $(0.27-1.23)$ & 0.156 \\
\hline High school & -0.68 & 0.51 & $(0.30-0.87)$ & 0.013 \\
\hline Vocational education & 0.04 & 1.04 & $(0.63-1.73)$ & 0.866 \\
\hline Higher education & 0.00 & 1.00 & (ref) & - \\
\hline \multicolumn{5}{|l|}{ Region } \\
\hline Almaty city & 0.37 & 1.45 & $(0.69-3.05)$ & 0.328 \\
\hline Almaty oblast & 1.51 & 4.55 & $(2.68-7.72)$ & $<0.001$ \\
\hline Kostanay oblast & 0.00 & 1.00 & (ref) & - \\
\hline \multicolumn{5}{|l|}{ High level of family support } \\
\hline No & 0.00 & 1.00 & (ref) & - \\
\hline Yes & -1.05 & 0.35 & $(0.22-0.55)$ & $<0.001$ \\
\hline
\end{tabular}


Table 4 Results of mixed effects logistic regression models predicting positive attitude toward ambulatory TB treatment, including interaction between level of TB knowledge and participant group (TB case, household control, community control)

\begin{tabular}{|c|c|c|c|c|}
\hline \multirow[t]{2}{*}{ Characteristic } & \multicolumn{4}{|c|}{ Positive attitude toward ambulatory TB treatment } \\
\hline & beta & OR & $95 \% \mathrm{Cl}$ for $\mathrm{OR}$ & $p$-value \\
\hline \multicolumn{5}{|l|}{ MAIN EFFECTS } \\
\hline \multicolumn{5}{|l|}{ Participant group } \\
\hline Community controls & 0.00 & 1.00 & (ref) & - \\
\hline Household controls & 1.03 & 2.79 & $(1.42-5.48)$ & 0.003 \\
\hline New pulmonary TB cases & 1.09 & 2.96 & $(1.44-6.08)$ & 0.003 \\
\hline \multicolumn{5}{|l|}{ Tuberculosis knowledge } \\
\hline Insufficient & 0.00 & 1.00 & (ref) & - \\
\hline Sufficient & 0.58 & 1.79 & $(0.89-3.61)$ & 0.102 \\
\hline \multicolumn{5}{|l|}{ Level of education } \\
\hline Primary and secondary school & -0.61 & 0.54 & $(0.25-1.15)$ & 0.112 \\
\hline High school & -0.73 & 0.48 & $(0.28-0.82)$ & 0.007 \\
\hline Vocational education & -0.02 & 0.98 & $(0.59-1.62)$ & 0.926 \\
\hline Higher education & 0.00 & 1.00 & (ref) & - \\
\hline \multicolumn{5}{|l|}{ Region } \\
\hline Almaty city & 0.44 & 1.55 & $(0.74-3.25)$ & 0.248 \\
\hline Almaty oblast & 1.52 & 4.58 & $(2.70-7.74)$ & $<0.001$ \\
\hline Kostanay oblast & 0.00 & 1.00 & (ref) & - \\
\hline \multicolumn{5}{|l|}{ High level of family support } \\
\hline No & 0.00 & 1.00 & (ref) & - \\
\hline Yes & 1.04 & 0.35 & $(0.22-0.56)$ & $<0.001$ \\
\hline \multicolumn{5}{|l|}{ INTERACTIONS } \\
\hline Sufficient knowledge $\times$ household controls & -0.63 & 0.53 & $(0.21-1.34)$ & 0.180 \\
\hline Sufficient knowledge $\times$ new pulmonary TB cases & -0.70 & 0.49 & $(0.20-1.23)$ & 0.130 \\
\hline
\end{tabular}

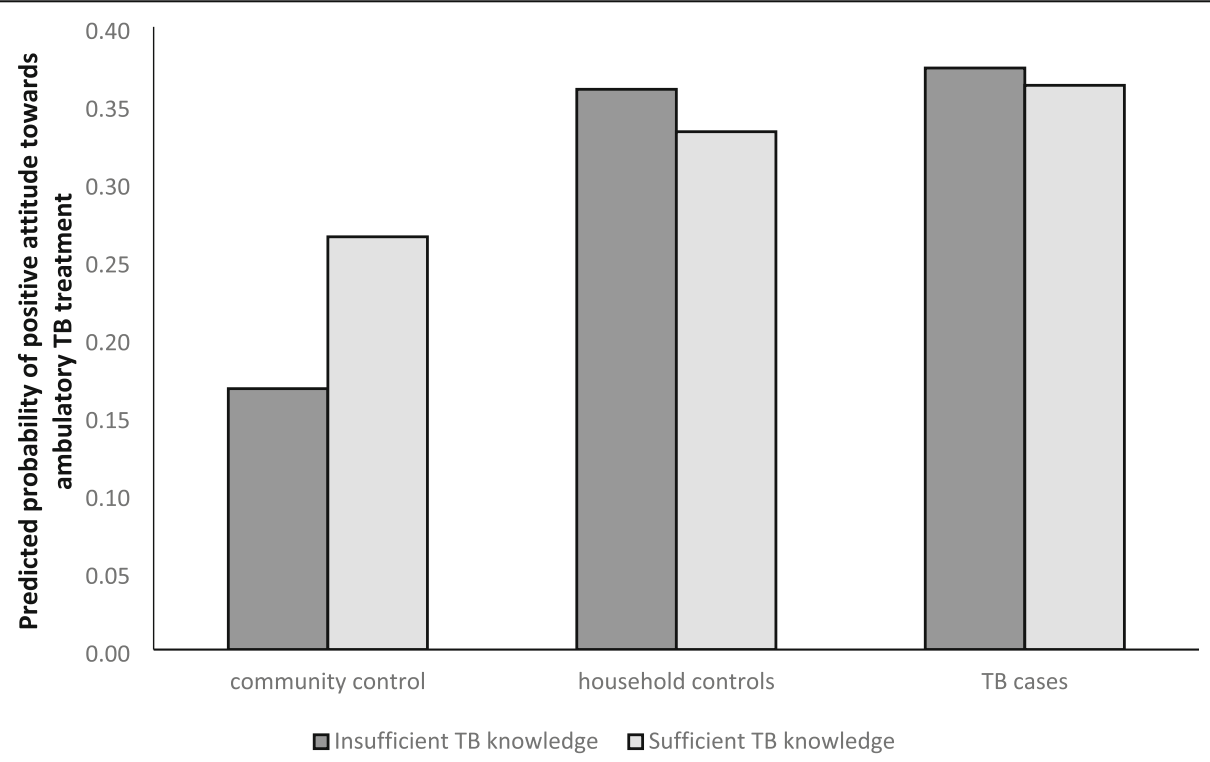

Fig. 1 Predicted probabilities of positive attitude towards ambulatory TB treatment from the model with interactions* 
symptoms, spread, and treatment were associated with more positive attitudes toward ambulatory TB treatment highlight the importance of continued education efforts.

Both TB patients and their family members had a more positive attitude toward ambulatory TB treatment than community controls, even in the face of insufficient knowledge about TB signs/symptoms, spread, and treatment. Ambulatory TB care gives TB patients more independence and helps to move treatment closer to places where patients live. In addition, administering TB treatment at outpatient settings might help to reduce the risk of nosocomial infection by resistant strains in hospitals [27]. Therefore, it is understandable that TB patients and their family members would view ambulatory TB treatment more favorably, although positive attitudes among these groups were still not nearly universal. TB treatment outcome and adherence are associated with level of social support including support from family members, partners, and friends $[28,29]$. We considered that people who had social support were more likely to continue treatment at home. However, we found that respondents with higher levels of support from family members and significant others were less likely to view ambulatory TB treatment favorably. These results may be explained by fear of transmitting the disease to family members or significant others at home. These findings have substantial practical implications for the development of ambulatory TB services. In particular, it is crucial to communicate that the appropriate control measures can minimize the risk of TB transmission to other people.

Another potential barrier is availability and access to TB medical services in rural areas where $43 \%$ of the population live [1]. We found that the number of TB patients supporting the ambulatory model of care was higher in Almaty oblast rural areas. Urban populations have better access to services and health care facilities (hospitals and policlinics), while the rural areas are characterized by a lack of all facilities and less developed infrastructure.

Comorbidities among TB patients [30], alhocol abuse, social determinants of therapeutic failure such as low income and low education [31] should be considered for the effective outpatient treatment.

To promote ambulatory $\mathrm{TB}$ care, the population should be informed about new treatment strategies which allow patients to rapidly become non-infectious. TB treatment outcomes in out-patient settings should be communicated to the general public to show that an ambulatory model of TB care produces at least the same results as in-hospital treatment. Such programs would reduce stigma against $\mathrm{TB}$ patients and provide necessary support from the community. Involvement of national leadership, mass media to reach target populations, and involvement of the local community are all required to create a truly effective campaign that takes into account cultural context and existing barriers. Educational programs on the route of TB transmission, signs and symptoms, consequences, prevention, types of treatment, and appropriate health messages are required to alter the negative social norms for a healthier society [32].

Multiple factors associated with TB treatment outcomes, organizational and structural barriers for TB services delivery must be addressed to successfully implement ambulatory TB treatment across Kazakhstan.

\section{Limitations}

Our study population of index-cases was limited to those diagnosed with TB and registered with the local TB dispensary and met our inclusion criteria, thus excluding all incident TB- patients with no family control. The study was conducted in three regions, which limits the generalizability of findings. Not all possible confounders may have been measured and included in the analysis.

\section{Conclusions}

More information and education campaigns about benefits of the new treatment strategy are needed to alter public opinion and attitude. Empowering communities through proper education would help to increase their TB knowledge and develop more positive attitudes toward ambulatory care of tuberculosis. Our findings can help to adapt and implement new treatment strategies in Kazakhstan and other Central Asia countries.

\section{Supplementary information}

Supplementary information accompanies this paper at https://doi.org/10. 1186/s12913-020-05413-0.

Additional file 1. Recruitment.

\section{Abbreviations}

MDR TB: Multidrug-resistant tuberculosis; NTP: National tuberculosis program; WHO: World health organization; DOTS: Directly observed treatment, shortcourse; KNSCP: Kazakhstan's national scientific center of physiopulmonology; CLS of NU: Center of life sciences of Nazarbayev university; ACASI: Audio computer-assisted self-interview; MSPSS: Multidimensional scale of perceived social support; GHRCCA: Global health research center of central Asia

\section{Acknowledgements}

The authors would like to sincerely thank all project staff members who contributed to the success of the project implementation, recruitment and data collection.

\section{Authors' contributions}

MT, BZ, MD conceptualized of the presented idea, developed the theory, verified the analytical methods and contributed to the interpretation of the results. MT supervised the findings of this work. AT, BZ, MD, NS administered and carried out the study. MD and MT wrote the original manuscript. NS, AT TM, MT edited and reviewed the manuscript. All authors discussed the results and contributed to the final manuscript. The author (s) read and approved the final manuscript.

\section{Funding}

CLS NU was the primary recipient of the research grant from the Kazakhstan Ministry of Education and Science. The Global Health Research Center of 
Central Asia (GHRCCA) of Columbia University was a research partner CLS NU as a subcontractor. Research reported in this publication was supported by the Fogarty Intrenational Center and the National Institute on Drug Abuse of the National Institutes of Health under Award Number D43TW010046. The content is solely the responsibility of the authors and does not necessarily represent of the official views of the National Institutes of Health.

\section{Availability of data and materials}

The data that support the findings of this study are available from CLS NU but restrictions apply to the availability of these data, which were used under license for the current study, and so are not publicly available. Data are however available from the authors upon reasonable request and with permission of CLS NU. Data requests may be sent to corresponding author at meruyert.darisheva@ghrcca.org

\section{Ethics approval and consent to participate}

The study was approved by Columbia University Institutional Review Boards (Protocol AAAJ8510), the National Scientific Center of Phthisiopulmonology (March 19, 2012) and the Center for Life Sciences of Nazarbayev University (Protocol 2-24 by April 17, 2012). Written informed consent was obtained from each study participant.

\section{Consent for publication}

Not applicable.

\section{Competing interests}

The authors declare that they have no competing interests.

\section{Author details}

${ }^{1}$ Columbia University Global Health Research Center of Central Asia, Almaty, Kazakhstan. ${ }^{2}$ School of Public Health, Department of Epidemiology and Biostatistics, University at Albany, Albany, NY, USA. ${ }^{3}$ Kazakh National Medical University, Almaty, Kazakhstan. ${ }^{4}$ Department of Epidemiology, Columbia University Mailman School of Public Health, New York, NY, USA. ${ }^{5}$ Columbia University School of Social Work, 1255 Amsterdam Avenue, New York, NY, USA.

Received: 27 January 2020 Accepted: 9 June 2020

Published online: 22 June 2020

\section{References}

1. National Statistics Committee. Social and economic development of the Republic of Kazakhstan January-February 2020. Available at: https://stat.gov. kz/edition/publication/month. Accessed 22 Mar 2020.

2. Global tuberculosis report 2019. World Health Organization 2019 https:// apps.who.int/iris/bitstream/handle/10665/329368/9789241565714-eng. pdf?ua=1 Accessed March 2020.

3. WHO Tuberculosis country profile: Kazakhstan. Available at: https://www. who.int/tb/country/data/profiles/en/. Accessed 22 Mar 2020.

4. Kohler S, Asadov DA, Bründer A, Healy S, Khamraev AK, Sergeeva N, Tinnemann P. Ambulatory tuberculosis treatment in post-Semashko health care systems needs supportive financing mechanisms. Int J Tuberc Lung Dis. 2014;18(12):1390-5.

5. Cox HS, Orozco JD, Male R, Ruesch-Gerdes S, Falzon D, Small I, Doshetov D, Kebede Y, Aziz M. Multidrug-resistant tuberculosis in Central Asia. Emerg Infect Dis. 2004;10(5):865-72.

6. Fitzpatrick C, Floyd K. A systematic review of the cost and cost effectiveness of treatment for multidrug-resistant tuberculosis. Pharmacoeconomics. 2012;30:63-80.

7. Smart T. Decentralised, patient-centred models of delivering treatment and palliative care for people with M/XDR-TB. HATIP. 2010;166:2-9 https:/www.aidsmap.com/pdf/ HATIP-166-October-8th-2010/page/1520450/. Accessed May 2016.

8. WHO. Global Tuberculosis Control 2011. http://apps.who.int/iris/bitstream/1 0665/44728/1/9789241564380_eng.pdf. Accessed August 2016.

9. WHO. Guidelines for the Programmatic Management of Drug-resistant Tuberculosis (2011). http://apps.who.int/iris/bitstream/10665/44597/1/ 9789241501583_eng.pdf. Accessed August 2016.

10. Heller T, Lessells RJ, Wallrauch CG, Bärnighausen T, Cooke GS, Mhlongo L, Master I, Newell ML. Community-based treatment for multidrug-resistant tuberculosis in rural KwaZulu-Natal, South Africa. Int J Tuberc Lung Dis. 2010;14(4):420-6.
11. WHO Tuberculosis country work summary. Available at: http://www.euro. who.int/_data/assets/pdf_file/0012/185889/Kazakhstan-Tuberculosiscountry-work-summary.pdf?ua=1. Accessed 26 Aug 2016.

12. WHO. Global tuberculosis report 2014. http://www.who.int/tb/publications/ global_report/en/. Accessed May 2016.

13. Healy S, Dietrich S, Roth T, Nyang'wa BT, Ducros P. Public health advocacy for the Berlin declaration on tuberculosis in the former Soviet Union: the view of Médecins Sans Frontières. Eur J Microbiol Immunol (Bp). 2012;2(4):282-6.

14. Ambulatory care sensitive conditions in Kazahtsan, WHO, 2015 http://www. euro.who.int/_data/assets/pdf_file/0003/294402/Ambulatory-care-sensitiveconditions-Kazakhstan-en.pdf?ua=1. Accessed March 2020.

15. Ministry of Health of the Republic of Kazakhstan. Order No. 994 from 25 Dec, 2017. Available at: https://online.zakon.kz/document/?doc_id=34545 994. Accessed 20 Apr 2020.

16. Comprehensive TB control plan in the Republic of Kazakhstan for 20142020. Available at: http://ccmkz.kz/upload/KAZ\%20TB\%20Complex\%2 OPlan\%20Final\%20Dec\%202013\%20RUS.pdf. Accessed 20 Apr 2020.

17. UI Haq N, Hassali MA, Shafie AA, et al. A cross-sectional assessment of knowledge, attitude and practice among Hepatitis-B patients in Quetta, Pakistan. BMC Public Health. 2013;13:448.

18. Anochie PI, Onyeneke EC, Onyeozirila AC, Igbolekwu LC, Onyeneke BC, Ogu AC. Evaluation of public awareness and attitude to pulmonary tuberculosis in a Nigerian rural community. Germs. 2013;3(2):52-62.

19. Hermosilla S, You P, Aifah A, Abildayev T, Akilzhanova A, Kozhamkulov U, Muminov T, Darisheva M, Zhussupov B, Terlikbayeva A, El-Bassel N, Schluger $\mathrm{N}$. Identifying risk factors associated with smear positivity of pulmonary tuberculosis in Kazakhstan. PLoS One. 2017;12(3):e0172942.

20. Davis A, Terlikbayeva A, Aifah A, Hermosilla S, Zhumadilov Z, Berikova E, Rakhimova S, Primbetova S, Darisheva M, Schluger N, El-Bassel N. Risks for tuberculosis in Kazakhstan: implications for prevention. Int J Tuberc Lung Dis. 2017;21(1):86-92.

21. Terlikbayeva A, Hermosilla S, Galea S, Schluger N, Yegeubayeva S, Abildayev T, Muminov T, Akiyanova F, Bartkowiak L, Zhumadilov Z, Sharman A, ElBassel N. Tuberculosis in Kazakhstan: analysis of risk determinants in national surveillance data. BMC Infect Dis. 2012;12:262.

22. Gilpin C, de Colombani P, Hasanova S, Sirodjiddinova U. Exploring TBrelated knowledge, attitude, behaviour, and practice among migrant Workers in Tajikistan. Tuberc Res Treat. 2011;2011:548617.

23. Wan T, Chukmaitov A. Social capital and use of folk and herbal medicine by older women in Almaty, Kazakhstan. Int J Public Policy. 2007;2(3/4):217-34. https://doi.org/10.1504/IJPP.2007.012904.

24. Zimet GD, Dahlem NW, Zimet SG, Farley GK. The multidimensional scale of perceived social support. J Pers Assess. 1988;52:30-41.

25. Mehret M, Mertens TE, Caraël M, Negassa H, Feleke W, Yitbarek N, Burton T. Baseline for the evaluation of an AIDS programme using prevention indicators: a case study in Ethiopia. Bull World Health Organ. 1996;74(5):509-16.

26. WHO. World Health Organization Tuberculosis control (1982). Report of a Joint IUAT/WHO Study Group. http://whqlibdoc.who.int/trs/WHO_TRS_671. pdf. Accessed August 2016.

27. Cox HS, Sibilia K, Feuerriegel S, Kalon S, Polonsky J, Khamraev AK, Rüsch-Gerdes S, Mills $C$, Niemann S. Emergence of extensive drug resistance during treatment for multidrug-resistant tuberculosis. N Engl J Med. 2008;359(22):2398-400.

28. Deshmukh RD, Dhande DJ, Sachdeva KS, Sreenivas AN, Kumar AMV, Parmar M. Social support a key factor for adherence to multidrug-resistant tuberculosis treatment. Indian J Tuberc. 2018;65(1):41-7.

29. Yin J, Wang X, Zhou L, Wei X. The relationship between social support, treatment interruption and treatment outcome in patients with multidrugresistant tuberculosis in China: a mixed-methods study. Trop Med Int Health. 2018;23(6):668-77 29691959.

30. Di Gennaro F, Marotta C, Antunes M, Pizzol D. Diabetes in active tuberculosis in lowincome countries: to test or to take care? Lancet Glob Health. 2019 Jun;7(6):e707.

31. Di Gennaro F, Pizzol D, Cebola B, Stubbs B, Monno L, Saracino A, Luchini C, Solmi M, Segafredo G, Putoto G, Veronese N. Social determinants of therapy failure and multi drug resistance among people with tuberculosis: a review. Tuberculosis (Edinb). 2017;103:44-51.

32. Stop TB Partnership (2001). Global plan to stop TB. Phase 1: 2001 to 2005. Available at: http://www.stoptb.org/assets/documents/global/plan/GLOBAL_ PLAN_TO_STOP_TB_2001_2005.pdf. [Accessed 26 Aug 2016].

\section{Publisher's Note}

Springer Nature remains neutral with regard to jurisdictional claims in published maps and institutional affiliations. 